Slavica

bruxellensia

\section{Slavica bruxellensia}

Revue polyphonique de littérature, culture et histoire

slaves

$4 \mid 2009$

Espaces slaves / espaces belges

\title{
Milan Kundera, Une rencontre
}

\section{Céline Magain}

\section{OpenEdition \\ Journals}

\section{Édition électronique}

URL : http://journals.openedition.org/slavica/292

DOI : $10.4000 /$ slavica.292

ISSN : 2034-6395

\section{Éditeur}

Université libre de Bruxelles - ULB

\section{Édition imprimée}

Pagination : 70-71

ISSN : 2031-7654

\section{Référence électronique}

Céline Magain, « Milan Kundera, Une rencontre », Slavica bruxellensia [En ligne], 4 | 2009, mis en ligne le 15 octobre 2009, consulté le 22 septembre 2020. URL : http://journals.openedition.org/slavica/292 ; DOI : https://doi.org/10.4000/slavica.292

Ce document a été généré automatiquement le 22 septembre 2020.

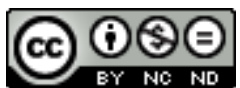

Les contenus de Slavica bruxellensia sont mis à disposition selon les termes de la Licence Creative Commons Attribution - Pas d'Utilisation Commerciale - Pas de Modification 3.0 France. 


\section{Milan Kundera, Une rencontre}

\section{Céline Magain}

\section{RÉFÉRENCE}

Milan Kundera, Une rencontre, Paris, Gallimard, 2009, 204 p. 
«...rencontre de mes réflexions et de mes souvenirs; de mes vieux thèmes (existentiels et esthétiques) et mes vieux amours (Rabelais, Janacek, Fellini, Malaparte...) » (p. 9)

2 C'est sur ces mots que le célèbre auteur d'origine tchèque Milan Kundera introduit Une rencontre, son quatrième et dernier essai en français, qui réunit de nouveaux textes et des anciens, réactualisés ou incorporés dans de nouveaux écrits. Comme le titre l'indique, il s'agit bien de rencontre, au sens propre comme au figuré. Elle peut donc être matérielle, intellectuelle, personnelle ou juste interposée, mais elle peut aussi se situer sur un autre plan, celui de l'humour, de l'ironie ou de la tendresse. Dans tous les cas, elle est le prétexte au dévoilement d'une pensée, d'une réflexion voire d'un souvenir poignant.

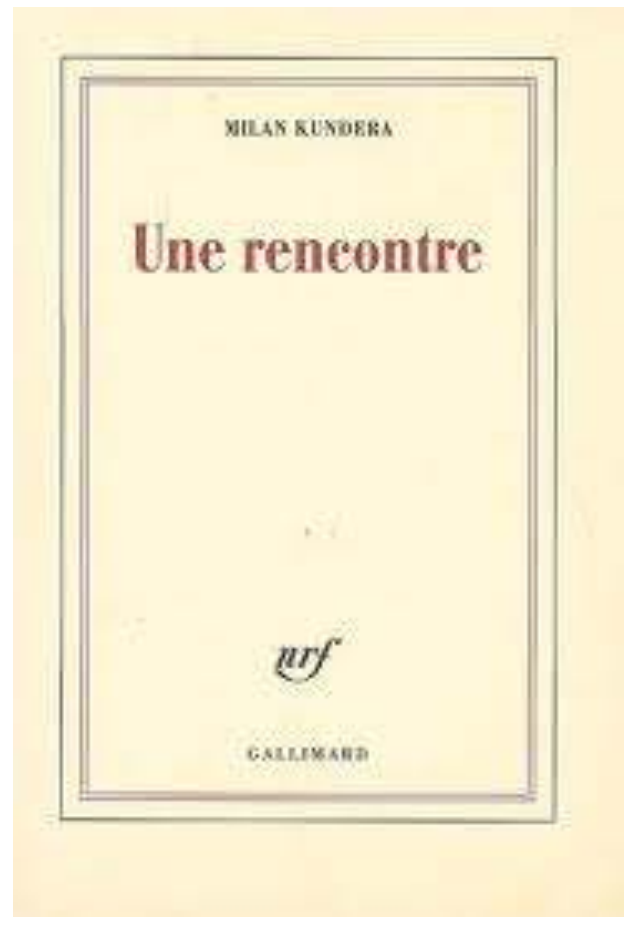

Dans les faits, Kundera mène le lecteur au gré de ses envies, le fait voyager d'artistes en musiques, de romans en peintures qui l'ont interpellé. Plus que montrer un ou plusieurs aspects d'une œuvre ou d'un auteur, il partage ce qu'il a vécu de la culture, dans un style simple, léger et très personnel.

4 Ainsi, sur le mode du flash-back, l'auteur évoque ce qu'il a ressenti devant l'œuvre de Francis Bacon, sa vision d'Anatole France par le biais des listes noires dans le milieu artistique, son incompréhension face à l'oubli quasi total de Schönberg, son questionnement quant à la répétition d'évènements historiques dans le contexte de la guerre en Tchétchénie, qui rappelle trop Hadji Mourat de Tolstoï, pour ne citer que ces exemples-ci.

5 Kundera transporte le lecteur, lui donne envie de découvrir et parfois de redécouvrir les œuvres dont il parle. Peu importe qu'il ait rencontré les artistes ou non, le sentiment d'être avec lui tout au long de ses réflexions reste présent. Ce n'est pas tellement un essai purement scientifique que Kundera propose ici mais une rencontre humaine et intellectuelle. Par cette humanité, le lecteur ne peut que vouloir connaître les auteurs abordés au fil des pages. Et la seule pensée qui l'habite est alors d'aller à la librairie la plus proche pour acheter les romans inconnus jusqu'alors et les dévorer au plus vite.

6 Même si cet ouvrage peut sembler parfois confus en raison de la multiplication des thèmes, l'enchaînement des époques, le mélange des lieux, sa qualité et son originalité s'imposent: il démystifie le texte en lui-même, ce qui justifie cette organisation particulière. Il montre que celui-ci n'est jamais fini, il démantèle son caractère absolu, il détruit son illusion de perfection. Tout comme le reste, il évolue avec le temps. C'est sans doute le message le plus important que le Kundera d'une plume mature et confirmée veut transmettre dans Une rencontre, le livre de ses quatre-vingts ans. 
INDEX

Index chronologique : XXe siècle, XXIe siècle

Mots-clés : littérature tchèque

Index géographique : République tchèque

\section{AUTEURS}

CÉLINE MAGAIN

Diplômée de Slavistique de l'Université Libre de Bruxelles 